\title{
Committee as Witness
}

\section{Ethics Review as a Technology of Collective Attestation}

\author{
Rachel Douglas-Jones
}

\begin{abstract}
This article explores the ethics review committee as a contemporary witness to the conduct of biomedical research. Ethics committee work is an internationally growing form of deliberation and decision making, a technology of anticipation that grants researchers access to experimental spaces, research funds and publication venues. Drawing on ethnographic work with a range of ethics committees across the Asia-Pacific region, I explore the metaphorical extension of logics of seeing into bureaucratic forms of ethics review. My analysis untethers the witnessing voice from an individual 'point of view', focusing on the attestive assemblage and its documentation. By exploring the committee as a form of collective attestation, I aim to show witnessing as a form of ethical work, for ethical ends.
\end{abstract}

Keywords: attesting, bureaucracy, committee, ethics, vision, witnessing

\section{Introduction}

On the second day of the 2010 Forum of Ethics Review Committees of Asia and the Western Pacific Conference in Shanghai, Dr Dipika took to the stage for her panel on continuing review practices. A microbiologist working at a research hospital in Mumbai, she stood to face the annual gathering on behalf of the research ethics committee she had served on for a number of years. Looking out across the hundreds of other committee members, she was sombre. Her talk described the death of a participant in an antibiotics study, an event which had prompted her committee to reassess its existing practices for following up on the research proposals that crossed their desk. In addition to reporting the participant's death as a Serious Adverse Event, as most committees in the room would have done, her committee had decided to make an effort to confirm the causality. When they did, Dr Dipika said, they found anomalies in the paperwork at the site. This, coupled with her committee's newly developed Standard Operating Procedures for visiting research sites, led to the instigation of regular checks on trials running under the 
committee's jurisdiction. From now on, she told the gathered conference-goers, if ethics approval was given to a study, members of the committee would be assigned to undertake a 'monitoring site visit', speak to staff and patients, and observe the site and the informed consent process. Comprehensive in its scope and designed to fulfil new requirements of the Indian Council on Medical Research, they hoped to keep better track of studies. As Dr Dipika spoke about the scheme, her voice became louder, faster and more agitated, the concern in it growing. She listed problem after problem that her monitoring team from the ethics committee had encountered during their visit, and for those gathered at the conference the list was startling. The protocol being used was not the same as the one approved by the committee. The informed consent sheet in use was not the one which had incorporated the committee's requested amendments. In addition to the participant death, there were further Serious Adverse Events that the principal investigator had not reported to the ethics committee. Patients' signatures were missing from the informed consent document. 'How can we rely on this data if the signature is missing?' Dr Dipika asked her audience. Worse, English-speaking patients had been given Hindi informed consent documents, using a translation that had not been approved by the ethics committee. 'I don't know what the integrity of the data is,' she repeated.

The discussion following her presentation erupted. Rather than expressing concern for the findings of the monitoring study, as Dr Dipika had perhaps expected, delegates took issue with the right and capacity of the ethics committee to do 'monitoring' at all. Several congratulated her on her committee's commitment to following up on their studies, but noted this was not a requirement of the World Health Organization's guidelines. 'It's not going to be easy for other ethics committees to do this,' noted one, 'because it's very intensive and requires expertise.' Others agreed, citing expense: 'I don't think even 1 per cent of the people in this room can do that'. Speakers worried about adding yet more tasks to the ethics committee, a body populated largely by volunteers. A delegate who had spent a good part of her career training clinical monitors to visit and assess the operation of clinical trials argued that it was already hard enough, 'difficult it is, to already just sit there as a member of EC [ethics committee] to do the job they're supposed to be doing well'. To add another task to the committee, the details of visiting the site and 'doing a good audit', she said, was simply a different area of expertise. ${ }^{1}$

Dr Dipika's desire to go and see the site where research was taking place is immediately understandable. Like Dr Dipika, ethnographers want to see for themselves, to hear and observe. As the editors of this special issue point out, witnessing is a matter of public concern, and affective power. Where reference to it is present, questions arise about who may witness, what qualities they must have, for whom they see, and the technologies their witnessing makes use of. But ethics review is an anticipatory exercise, taking place in advance of the research itself. While committee members regularly wonder what becomes of studies that pass over their tables, Dr Dipika's innovation is not just an example of a committee reaching beyond its initial mandate of reviewing a protocol. It is also not just a case of a very literal interpretation of the principle of 'continuing review'. It reveals a belief that going 
to see, to personally experience a setting, offers greater contact with the world of research and what is happening in it.

In this article, I tie together this idea of witnessing, the in-person experience that Dr Dipika sought, with the institution of the ethics committee as a global form of (anticipatory) decision making on biomedical research. Despite the obvious appeal of monitoring activities, my argument does not emerge from the experiential logics she invoked by visiting the sites where research was taking place. Instead, I am interested in the logics that make up the work of seeing a research proposal, and providing ethics approval before research itself happens. I argue that the logics of an ethics committee are rooted in visual cultures, and that through its form, composition and actions, the committee relies on spatial and temporal forms that underpin its capacity to speak. To explore the work of ethics committees through the lens of witnessing allows us to perceive how bureaucratic forms encode ideals of proximity and distance, forcing us to examine the location, history and practices of this social body. As the editors argue, to foreground the structural, relational, material and performative dimensions of witnessing (Chua and Grinberg, this issue) means looking into sites where witnessing may be more diffuse, contested, (re)mediated or, indeed, tacit. At the heart of my analysis is a story that metaphorically extends specific, informed and authoritative ways of seeing into bureaucratic forms of ethics review. Through this extension, I argue, emerges a committee that can do the work of witnessing research yet to come.

For the past ten years, I have studied the work of the regional NGO who hosted the conference at which Dr Dipika spoke that autumn in 2010. Their mission, now as then, is to develop capacity in ethical review through training up (primarily biomedical) research ethics committees, who are based either in universities or in research hospitals. The NGO, the Forum of Ethics Review Committees of Asia and the Western Pacific (or FERCAP hereafter), was set up in 2000 with the specific purpose of generating the skills and abilities within institutions to conduct ethics review. Funded through initial grants from the World Health Organization's Tropical Disease Research arm and support from the US Seattle-based PATH, which until 2014 stood for the Program for Appropriate Technology in Health, the NGO today has twenty years of experience running local training workshops in how ethics committee work operates. Its growing network of members have supported one another across the Asia-Pacific region as they work to set up and improve the operations of their own committees. As such, my fieldwork has taken place in what George Marcus calls a post-Cold War 'regime of intervention' (2005: 32), where this NGO seeks to intervene in global inequalities of review capacity (DouglasJones 2017). This intervention originates in the leadership of two women from the Philippines and Thailand, operating with and through global networks of their own construction. Their objective has been not only to support research happening in the 'South', but also to ensure that research collaborations that take place between the well-resourced and funded researchers in Europe and North America are met with informed and critical counterparts in lower-income settings. Since the majority of biomedical research (and all involving human subjects) cannot go 
ahead without ethical approval, something only an ethics committee can provide, I have followed the kinds of activities going on to ensure access to these research worlds. I participated in training and surveying teams, from Sri Lanka to Thailand, on to the Philippines, Taiwan and Mainland China, and it is from this multi-sited material that I have come to see committees as doing the work of witnessing 'good' science, through their form, content and voice.

Over the years, my analysis has developed into a consideration of the ethics committee - known in the United States primarily as an Institutional Review Board (IRB) - as a global decision-making form, concretely (if varyingly) described in documents, policies and regulations, enacted through meetings. The histories of how committees are integrated into research and clinical practice are national, but their role in placing ethics at the gateway to the making of 'good science' is international. Committees are now obligatory points of passage for all research with what in the United States is termed 'human subjects', at home in the audit cultures and virtuous bureaucracies of the late twentieth century (Jacob and Riles 2008; Strathern 2000). I conceptualize the work of committees through the analytic of witnessing by placing their practices in a longer history of witnessing within scientific research. Historian of science Steve Shapin, in his writings about polymath Robert Boyle's early experiments with an air pump, describes in detail the work - material, political and social - that went into generating scientific methodology. Boyle insisted that the witnessing of experimental work was 'to be a collective enterprise ... the reliability of testimony depend[ing] crucially upon its multiplicity' (Shapin 1994: 488), and the written word became a crucial element in communicating witnessed experimentation. Taking up this story, Donna Haraway deals critically with the witnesses Shapin identifies as so central to the seventeenth-century project of emergent scientific method, showing how features of trustworthiness - the modest witnesses - resided in gendered norms that continue to shape knowledge making: whose accounts can 'lose all trace of their history as stories, as products of partisan projects, as contestable representations, or as constructed documents in their potent capacity to define the facts' (Haraway 1997: 24)? Just as it mattered who assembled to attest to the making of a scientific fact (Haraway 1997), I explore how it matters who is assembled to assess research proposals before they are put into practice. As we shall see, the job demands skilled expertise, an expertise willing to make itself subsequently constitutive yet unidentifiable in a committee decision.

Now, witnessing is not a term that committee members I worked with use to talk about their activities. Witnessing can, doubtless, be an ethical moment or life project. Indeed, the political theorist Michal Givoni argues in her work that witnessing has undergone a transformation from domains of legality and faith to become a 'social vocation in its own right' (Givoni 2014, 2016). Many who serve on biomedical research ethics committees do consider their task through a broader lens of justice: improved health outcomes, better treatments, and more cures for people they will never meet. The kind of research they wish to make possible, from global cancer trials to neglected and tropical disease studies, comes with an often tacit yet inter-generational logic of continuous improvement in human wellbeing. 
So while we could think about witnessing as a form of ethics (e.g. van Dooren on witnessing as ethics [2004] or Bird Rose on becoming-witness [2015]), my argument focuses more specifically on ethics - in its bureaucratic instantiation - as a form of witnessing.

In illuminating everyday committee practice, I draw on ethnographies of another international NGO, Médicins Sans Frontières (MSF) (Fassin 2008; Redfield 2006).Peter Redfield and Didier Fassin's analyses of the witnessing work and ethos of MSF share with my fieldwork a valorisation of the distant, professionalized viewer, one for whom an idea of objectivity hovers. However, as I go on to show, there are important and interesting departures. My argument proceeds in four parts. I am interested first in how the collective vision of the committee develops. Research ethics, while practised in scientific domains, does not have clear-cut answers. Yet answers must be arrived at. As I will argue, there is translation of ideals of vision into the bureaucracies of ethics committee practice, which tie its operation to scientific histories of bearing witness. Second, I put together witnessing and secrecy. As the sociologist Laura Stark has pointed out from her work with ethics committees in the United States, few are open to observation (Stark 2012). Few members share publicly their committee experiences, and the testimony as a mode of witnessing their work is rare. This raises questions for the kind of assessment that takes place. Third, I explore how voices that will not abide by the conditions of collective voice and closed decision can result in what one interviewee called 'martyrs of the committee. What does it mean in this setting to trace an alternate etymological route of witness into the terrain of martyrdom? Finally, arriving at the committee's approval letter as the eventual product of their assessment, I develop an analysis of committee work as attestation. I differentiate witnessing and attesting to discuss the double meaning of making 'good' science. In each section, I draw out a different facet of the committee as witness, with the committee constituting a technology that reveals ethics committee work as a specific mode of witnessing. My aim in assembling these facets is to sketch an understanding of how a committee - a group of people sitting around a table - comes to speak as one; to illustrate the kinds of imaginaries of representational politics that are embedded within the form of the committee; and to illustrate how these are continuous with regimes that tie together vision and knowledge in the making of legitimate decisions.

\section{Where do research ethics committees come from?}

Ethics committee work is an internationally growing form of decision making, a technology of anticipation that grants access to experimental spaces, research funds and publication venues. While medical ethics has long histories in a vast array of healing traditions, the making of documents concerned with experimental research has a history spanning the last decades of the twentieth century, and is just beginning to be written. In North America, ethics committees were part of a discourse about restoring 'trust' and participation in research following research scandals (Stark 2012). In the United Kingdom, the social historian Duncan Wilson's work has examined 
shifting power relations and expertise in the workings of medicine through the emergence of bioethics during the era of audit cultures (2014). Most importantly for my purposes here, research itself was also undergoing international changes. During the 1990s and early 2000s, research efforts became increasingly global in their reach and collaborative scope. Pre-existing concerns about the testing of new substances on the research bodies of 'elsewhere' intensified, raising questions of variable ethics (Petryna 2005, 2009). In a biomedical context, research is itself taken to be a response to human suffering: it is a given within the Declaration of Helsinki (World Medical Association [1964] 2013) that research on humans is a necessary condition for the development of drugs to alleviate that suffering. But these interventions on human bodies - healthy and sick - have, throughout the twentieth century, also been sites where what will be acceptable forms of research are negotiated.

International documents agree that committees local to the research are important, and should exist. In the early 2000s, this was called 'dual ended' review, with the UK's Nuffield Council on Bioethics (2002, paragraph 8.22) recommending that all research should be reviewed in both the sponsoring country and the countries where the research will take place ('hosts'). During the first few years of my study of ethics committees outside of Europe and America, the European Medicines Agency (EMA) put the demand for 'local' ethics review committees most strongly in their 2012 report:

A clinical trial should not take place in a country in the absence of a review by an Ethics Committee in that country. If such a committee does not exist it should be established as a pre-requisite before the trial takes place. (EMA 2012:17)

The presence and role of committees is an ongoing topic within revisions to international guidelines (CIOMS 2016). In their 2018 Global Code of Conduct, the European Commission coined the concept of 'ethics dumping', which they used to point to the risks occurring when 'research with sensitive ethical issues is conducted by European organisations outside the EU in a way that would not be accepted in Europe from an ethical point of view' (EC 2018). The term 'ethics dumping' developed as a way of giving name to inequalities of power in research collaborations, namely that research unacceptable in the country of the researcher (or funder) might be taken elsewhere in the world to be conducted (Nordling 2018).

But what is an ethics committee actually evaluating? There is widespread agreement that if research is not scientific - if it will not produce scientifically valid findings - then it is inherently unethical. Ethics assessments and scientific assessments are intertwined at a basic level. The Nuffield Council on Bioethics pointed to this challenge when they followed up on their 2002 report. Participants in the discussions agreed that both a proposal's scientific quality and ethical issues should be reviewed, but, as they reported, 'there was disagreement as to how this should be achieved. Ideally, and where feasible, it was suggested that these review processes should be separated' (Nuffield Council on Bioethics 2005: 48). Desirable though the separation may be, it is not always 'feasible'. Ethics review has been differently insti- 
tutionalized, with some committees receiving only protocols that have gone through a scientific review, and others not. Nuffield participants noted that in a small country such as Fiji, 'there are not currently enough suitably qualified experts to make it possible to create two separate committees' (Nuffield Discussion Paper 2005: 48). The discussion paper concluded that an ethics committee had a 'duty' to ensure that both the scientific and ethical aspects of a proposal were reviewed, 'rather than stating how this should be achieved' (Nuffield Discussion Paper 2005: 48).

In this way, ethics committees come into a more familiar history of science: in bearing witness to the scientific validity of the protocols on their table, they are not bearing witness to the making of a fact but to what can be sought as knowledge. This has not gone unnoticed by scholars, causing complaints of censorship (Hamburger 2004), and, in Stark's memorable phrase, ethics committees 'are consequential because they affect how researchers go about creating knowledge - and, as a result, the kinds of things that are knowable' (2011: 234, emphasis added). Ethics committees' attention to matters considered scientific can frustrate: 'clinical researchers', wrote neurologist and clinical trial researcher Charles Warlow, 'are exhausted by the demands of ethics committees that seem more concerned with the science (which they cannot necessarily judge) and editorial control of patient information sheets than with ethics' (Warlow 2004: 241). I want to emphasize that this separation of science and ethics is not only a matter for committees in countries with fewer experts. It is a dilemma of expertise more broadly: the questions of a study's sample size demand the presence of a statistician; uncertainty about new methods leaves members wondering what knowledge will arise from the study. Few committees have the expertise to address everything that arrives on their tables. But can, and should, committees be expected to act as what Jacobs calls 'epistemic filters' (Jacobs 2019)?

Dr Dipika's story, with which I opened, takes us to the position of the research ethics committee poised between assessment and action, its relationship to (auditable) documentation and its temporal nature of anticipation. ${ }^{2} \mathrm{Her}$ initiative reminds us that committees are not present when research is being conducted, and few have the resources to do 'follow up' work. But it also reminds us that committees are collectives. Their assessment is not the view of a single expert, moving out into the field to observe. Their assessment, as I shall go on to argue, falls within the complex domain inhabited by other nongovernmental actors, whose witnessing is tied to institutional, professional and ethical subjectivities. Let me introduce the character of their assessment by returning to my ethnography.

\section{Collective vision}

A plastic water bottle was the device used to introduce me to how a committee sees. I encountered this water bottle at Thammasat University, Bangkok, on a hot April day in 2010. Through the lunch break of a training course, over piles of lychees and rambutan, I spent time quizzing my patient interlocutors, Juntra and Cristina, about the topic that had for some time been my empirical focus: decisions in ethics 
review committee meetings. Deep into our dialogue about the kinds of expertise that committees often convened, Juntra declared with conviction something I found rather surprising. Committee members should, she said, avoid the kind of discussions which led to position taking:

In a debate, if you adopt a position, you take that and see if you win or lose at the end. You won't compromise. But it's not about winning or losing, that's not a good attitude for an ethics committee.

Cristina agreed:

It's not who you are, [if you take a position] you won't be moved, so it's not what you really think. Real life is about decisions, not hypothetical unreal stories. If, instead, all of you have one position, how to contribute to the protocol - if you have that position, you can have your eyes open for another's view.

Juntra, who was sitting opposite me, pointed to the water bottle between us to illustrate the point. 'I can't see the other side of the bottle', she said. 'Our job, is to ask, "How can we describe the whole bottle?"

Now, it seems like Juntra and Cristina are asking for different things. They don't want committee members to take 'a position', seen as something that makes members unable to compromise. But they do want everyone to have a single purpose: to contribute to the protocol. This, Cristina suggests, can make the view of others available. In her demonstration, Juntra intends the bottle between us as the applicant's protocol, forcing the bottle into view not only from the literal perspectives of those around a table at an ethics committee meeting, but also their figurative perspectives. That she and I can literally see different sides of the bottle is equated with the different (figurative) 'perspectives' that the members on the committee will bring to the discussion: they may have clinical experience; they may have knowledge of the law. The ideal discussion of an ethics committee, at least according to this lunchtime lesson, is able to describe the whole bottle - the whole protocol - and what it looks like 'seen from all sides'. This curious imagined view of the protocol is one which finds resonance with 'a kind of cubist presentation in which every side of the object is presented simultaneously to us in a single - though "general" - perspective' (Holbraad and Willerslev 2007: 334). Turned into a 'general' perspective, the committee's discussion finds its eventual resting form in a documented decision. Yet it is also an aggregative logic that wants to both clock up the geometric angles of a circle in search of a view from 'everywhere', to 'allow people to participate in loose and temporary formations that can be done and undone according to different political, affective or epistemic affinities', as Andrea Ballestero has put it (2017:34). It wants the single view eventually produced to be a synthesis by virtue of each member removing themselves from their own perspective to take on the same task: 'how to contribute to the protocol'.

What kind of seeing is going on here? Seeing, as we know from countless histories of science and ethnographies of making-visible, is a tricky thing (Coop- 
mans et al. 2014; Strathern 2014). From optics to the scientific persona, it is often technologized, individualized and moralized (Daston and Galison 1992), tied to the personhood and ambition of a researcher. Yet for all the analyses that we have of vision and gaze, few have asked how a collective sees. Redfield's analysis of Médicins Sans Frontières, the humanitarian organization known in English as Doctors Without Borders (2006), does so by centring on their evolving tradition of 'temoiniage', arguing that as an NGO, with specific forms of medical expertise, they offer a 'collective, expert witness to disaster, detailing as extensively and precisely as possible the anguish of the world' (2006: 19, emphasis added). Like Redfield, I am working in a space of nongovernmental organizations, and with a field that often explicitly addresses questions of inequality, justice and the alleviation of suffering. Unlike Redfield, the collectivities I am ultimately discussing are not organizations or individuals, policies or modes of speech, but specific, standing groupings of around eight to ten people. They are committees. I agree with his insistence on 'recognising the collective nature and technical capacity of contemporary moral agents' (2006: 5): these are groups of experts, whose authority rests on their collective character (Lamont and Huutoniemi 2011). To ask how a committee gains its capacity to see, we must ask what techniques of the visual make up its eyes. Based on Juntra and Cristina's lunchtime lesson, my initial argument is that a visual logic of seeing from 'all sides' underpins the committee's imagined vision, and thereby its legitimacy. This notion of seeing from all sides puts the committee's assessment into a history of objectivity in which an objective gaze is moralized. What Juntra and Cristina are asking for is a uniquely disciplined expert, present for their expertise, who is actively ensuring that their individual view is open to being informed through discussion. To witness, here, is not merely to see the proposal. It is to see it in a certain way, and to produce - through the social technology of the committee a document with a decision. This is what Redfield calls a 'representational persona, one that can function as a credible advocate of particular truth claims' rights' (2006: 5). The claims of such a person in his work emerge within a 'larger system of global media and a legal discourse of human rights' (Redfield 2006: 5), whereas the 'larger systems' of ethics review concern the protection of human subjects that will participate in research. The ethics assessment takes place in a space of anticipation. Thus, the nature of the knowledge they produce is suspended - the viewpoints that went into making a decision are obscured - and it is not always possible to discern from a decision where it might be contested.

\section{Witnessing in secret}

While histories of ethics committees root their activity narratively in the evaluation of research on behalf of publics and in the interests of participants, they are nonetheless known for their closed proceedings. It is not at all easy to find out what they see, or how they do their work. Committees are closed to the point that, observing from their country of origin the United States, Laura Stark's ethnography of three committees and their deliberations took the title Behind Closed Doors 
(2012). As ethics committees have been founded and run elsewhere in the world, this characteristic has led to questions being asked more openly about their operation and constitution. A 2009 editorial by the ethics expert Amar Jesani ${ }^{3}$ in the Indian Journal of Medical Ethics criticized the 'silence' on the operation of ethics committees. 'Why is it', he asked,

that even 30 years after ECs were first established in India, we do not have even experiential accounts (let alone systematic studies) on ECs in the public domain? Why have EC members not narrated the challenges and dilemmas they have faced, and discussed how to make regulations effective? (2009: 2)

With Jesani, we might ask why a process ostensibly designed to provide public reassurance that biomedical research is ethically sound is so closed to scrutiny? One answer is that in the biomedical industry, revealing research intentions before they become reality is a competitive disadvantage to which few would consent. Another is that if present, observers would influence the capacity of members to speak freely, and critically, about the proposals on the table in front of them. The translation of visual culture into the committee here is the argument that to do its work, the committee must itself be unobserved. Its independence and its capacity to speak to itself is dependent on its work behind closed doors. The anticipated gaze is not merely a gaze of knowledge (as for Juntra and Cristina above); it is, as the political scientist Yaron Ezrahi puts it, a gaze that shapes action (Ezrahi 1990: 101). Jesani is clearly interested in establishing systematic and nationwide knowledge across India about the work ethics committees do. But the question underlying his appeal is this: how can ethics work be socially accepted as a form of witnessing to good science, if that act cannot itself be witnessed? Ezrahi's reference to the expected effect of the gaze upon conduct has direct implications on the effect of witnessing on the witnessed: to witness the witnessers would make their work of witnessing impossible.

As Shapin and Schaffer note in their classic history of the Enlightenment foundations of modern science, Leviathan and the Air Pump, 'democratic ideals and the exigencies of professional expertise form an unstable compound' ([1985] 2011: 336). Ethics review is the domain of professional expertise, but it also carries ideals of lay participation in the governance of science. Yet in the absence of the cornerstone of 'transparency' in committee practice, the role of public input gets into ethics deliberation in other ways. In his analysis of science and democratic reasoning, The Descent of Icarus, Ezrahi observes that scientific and political reason share visual languages. 'The notion of politics as something observable,' he writes, 'has come to uphold in America a conception of accountability which rests on the complementary requirements ... that actions taken by political agents be made transparent to the public and that citizens act as competent witnesses and judges of the exercises of political power' (Ezrahi 1990: 99). In my case, citizens are not called upon as witnesses of committee work. Indeed, their capacity to view the reasoning of the committee is limited. As we saw above, committee members cannot (ordinarily) be (individually) heard: their voices come together in the creation of a 
collective vision. And meetings are closed. So, it is to committees themselves that the work of witnessing scientific proposals is put. But concern regarding silence of members produced through the committee's collective speech is also interesting for from whom this question of openness comes. Witnessing and secrecy might seem antithetical, belonging to opposite ends of a perceived spectrum of transparency. Surely to witness goes beyond seeing, into the capacity to reveal?

\section{'Martyr of the IRB'}

The committee does its work of seeing in a protected space, a space that arguably offers members the capacity to speak freely. Needing this space, however, indicates that members of an ethics committee are not, actually, expected to be fully disinterested. In the process of a committee meeting, even if Juntra and Cristina's ideal performance of decision-making-through-common-positionality is followed, people may and should disagree with one another. Although I have discussed the role of the scientific assessment the committee must often make, their collective role is to speak for the research, and for the communities in which it will be conducted.

Following FERCAP's work across their region of operation led me to a large hospital on the west coast of Taiwan. Here, in 2010, I sat down with Camilla for lunch. Camilla, a colleague of my local host, had just arrived back on campus from a nearby hospital where she had given a talk to doctors about the ethics of genetic research. 'I went to threaten them!' she said, laughing, as we ate food from the nearby canteen. She wanted to make her classroom of researchers more aware of questions of privacy and the relevant regulations in Taiwan. 'I can't tell how much they change[d]', she told me, 'but gradually, I think they change their thinking of ethics':

Medical doctors, they think of research; [the] patient, who cares? A lot of MDs, their mind is set on research but not really ethics. They might not think of it at all, before someone convinces them. Sometimes it is hard to change their attitude or thinking. Sometimes they still argue. It's a long time process to educate these people. Even in a committee you find doctors still doing things very unethically - after all the education, I am always shocked that you still see these kinds of people around, still.

I asked her to elaborate on 'these kinds of people'. She shrugged, and told me she herself had once been one of them: 'When initiating a research [project] we'd do unethical things, for consent - ignore things we were supposed to do. Just say "Hey, give me my proof - my IRB approval letter". [Then] forget everything about ethical things'. As we talk, her criticism is initially aimed at researchers, as she speaks from her more recent role as an educator. But soon she begins to extend her critique to the committee she now sits on, suggesting that under pressure, committees bend to the expectations and demands of their colleagues:

The hierarchy system is very strong and people are afraid to lose their job. Committee is a nice way to do this, 'cos we have backup from each other. We can speak out. [We are] not afraid to have a 'big mouth'. 
In my research conversations to that point, committee members had previously confided difficulties in speaking out or expressing concerns, but this was the first time someone had drawn explicitly on the committee as a collectivity ('we have backup from each other') as a way of establishing the authority of a committee against the authority of a (senior) researcher. The idea of a committee capable of making a critique from a position of common agreement seemed to tilt Camilla's narrative of silenced voices in the face of steep institutional and professional hierarchies. But after this outburst, Camilla fell silent. She reflected for a moment. And she changed her mind. Her account of the committee challenging authority through group discussion dissipated as she went on to reveal that it was in fact her enactment of this ideal of speaking out that led to her becoming an $e x$-member of the committee. 'Well, actually I was kicked out!' she exclaimed, with a wry smile.

They [the committee] want smoothly run, obedient ones. [For me] it's about whether, at the right time, are you willing to speak up for something. Especially for ethics. You're supposed to speak up. That's our principle. It's the right thing to do, for myself and participants. You set your mind on the ethical thing and you do it. Not different to becom[ing] a martyr. I'm a martyr of the IRB! Honesty, integrity, things you believe in.

Camilla's invocation of martyrdom reminds us of a different etymological route for the witness: martyr. Fassin, relying on Giorgio Agamben, points to the Greek translation of witness as martyros (Agamben 1999: 31, cited in Fassin 2008: 541), a connection noted too by Derrida, who tells us that 'Greek makes no explicit reference to [...] surviving, to presence' (Derrida 2005: 75). The witness is the 'sacrificed person', Fassin writes; 'the sacrifice of his life bears witness' (2008: 541). Now, Camilla does not give up her life, and certainly does not face the kind of death Fassin is describing in his article. But she leaves the committee rather than betray her idea of what ethics should be. She is, perhaps, a martyr to her ideals, but to her, it is her martyrdom that allows her to witness. In Fassin's analysis, firmly in the realm of physical over, say, social death, 'the martyr bears witness without speaking' (2008: 541). We might see that Camilla's insistence, her immovability, has shifted her from a position of expertise into one of 'mere opinion', removing her from a factual style into what Haraway, in her analysis of the immodest witness, has termed the 'flourishes of a human author' (1997: 26). She sees herself as bearing witness to ethics by remaining true to her ideals; she is seen by the committee as having diverged from the necessary capacity to bear witness as a part of a collective. Was Camilla 'immodest', and for whom?

\section{Assembling attestation}

In this final section, I build on my discussions above to suggest that the personal function of the witness becomes the attestive work of the group. As I noted earlier, a committee can seem poised between assessment and action. As many who have submitted proposals to their own university or hospital committees know, this 
moment of suspension resolves at the end of their review process, when a committee provides a stamped document. This document can then be used by the researcher to assure funding bodies and journals that a review has taken place. In this shift from discussion to document, often effected in practice by the committee's chair and secretary, ethics becomes something that can be obtained and proven through stamps and certificates (Jacob and Riles 2007). Analytically, I suggest that the document generated untethers the committee's work from its series of points of view and mobilizes an attestive assemblage into the voice of the committee, which then, as one lecturer put it during fieldwork, 'speaks as one' (2011: 235). By choosing to think of committee documentation as attestation (over testimony or witnessing), I am pointing to the non-narrative nature of the document, its 'thingness.' However, unlike the 'modest witness' of the gentleman scientist variety (Shapin 1994), this collective entity does not simply retire from view. Remaining in view as a committee, in the absence of access to their deliberations, membership becomes the primary means by which those not party to discussions assess how well a disinterest that is not dislocated' (Redfield 2006: 17) has been achieved. The legitimate attestation rests on who has looked at the proposal. An example will illustrate.

During the Shanghai FERCAP conference where Dr Dipika presented, the conference members also spent a full afternoon in the large, darkened auditorium discussing language on the soon-to-be revised World Health Organization guidelines for research ethics committees (WHO 2011). Among many points of contention was a sentence regarding specifications of membership. Should the new guidelines specify that members should 'represent' the communities where research will be conducted? Is it sufficient to specify that they 'reflect' those communities? Or must they have 'knowledge of' them? A committee is at a (careful) remove from those with whom proposed research will be conducted. This distance is managed through the composition of the committee. Having someone knowledgeable of the law is deemed necessary, and persons with knowledge of the communities in which the research will take place are seen as central to legitimate and informed decisions. Yet during discussions of what language to use in international guidelines, committee members at the conference in Shanghai go back and forth for hours. Was representation 'too political'? Was 'having knowledge of' too distant? What did 'reflection' even mean?

From the United States, Stark describes how 'administrative documents force people to identify as a given type', something she calls a 'constitutive perspective', from the ways that formal records help constitute new types of people (Stark 2011: 237). This 'constitutive perspective' has certainly entered international recommendation documents, which specify the types of person a committee ought to contain. It is also visible in the discussions between representing and reflecting populations with whom research will take place. At stake is what members of committees know, and how they know it. Yet within this article's argument that what members are doing is witnessing work, there is something further occurring in the discussion over terminology. These shifts in vocabulary between representation, reflection and 'having knowledge' echo a divide in the root of witnessing, something that Fassin 
has elaborated as a distinction between the knowledge of the observer and the participant. As Deborah Reed-Danahay summarizes, this separates those who give an account 'on the basis of his observation, the other on the basis of his experience' (Fassin 2011: 204, cited in Reed-Danahay 2017: 62). As committee members debate the distinction between 'representation', 'reflection' and 'knowledge of' prospective research populations, at stake is the question of whose knowledge need go into the eventual assessment. Must members have experienced life in the way likely participants will? Or is it sufficient that they 'have knowledge' of it? Much as this is a discussion of 'constitutive perspectives', it is also a debate over what will count as the correct combination of observers and participants on a committee. When the product of a discussion is documentation, committee composition becomes the referent for that document's capacity to fulfil its attestive role. Declaring the proposed research 'approved', the committee enacts its role as pre-emptive witness of both scientific and ethical concerns.

\section{Conclusion}

As ethics committees have been set up across the world, their members today participate in a now global regime of knowledge making, approving both study designs and ethical considerations of prospective research. In the passages above, I have shown why committee work belongs in a genealogy of knowledge making that can be productively understood through the lens of witnessing: it is anticipatory, it depends on ideals of disinterested yet motivated vision, and it has the power to generate a collective voice through which to speak.

Returning to my opening story, when Dr Dipika proposed that committee members enter the rooms and laboratories of researchers she was met with widespread dismay: not that kind of witnessing! Her suggestion to relocate the practices of committee witnessing made visible that the attestive work of committee members happens before research takes place - in the committee meeting. In this meeting, following Juntra and Cristina's own theorization of a committee's capacity for collective vision, we learn where a committee member should 'stand' during discussions. This key gives us access to committee work as an attestive assemblage, untethered from the model of an individual point of view or subject position. Released and reconstituted, the committee speaks a voice that obscures the specificities of the voices that underpin its legitimacy. Whereas the witnesses of early science benefited from the protections of rank, class and gender, the anticipatory witnesses of an ethics committee operate under the conditions of partial obscurity. Thus, the committee generates an authoritative assessment, the product of combined but concealed expertise, a 'mirror of reality that reinforces its own un-motivated veracity even as it transmits a distinctly moral framing vision' (Redfield 2006: 17). Placing the committee as witness within longer traditions of scientific witnessing, we can see afresh the logics of vision that come to constitute its view.

The eventual documents that committee members author allow the prospective future contained in a research protocol to move ahead. By considering their bureau- 
cratic work as bearing witness to what 'good' science will be - both scientifically, in terms more familiar to historians of science, and ethically, as their name suggests - I bring the tacit logics of vision and voice back into view as constitutive of approval processes. Thus, research futures - as they pass over the tables of ethics committees - emerge through the ideal that committee work will indeed be witnessing work; that it will be ethical work, for ethical ends.

\section{Acknowledgements}

Research for this paper was conducted under the International Science and Bioethics project, Economic and Social Research Council, UK (ESRC RES-062-23-0215). The author wishes to thank Liana Chua and Omri Grinberg, along with the journal's anonymous reviewers, for their constructive and clarifying readings of my argument.

Rachel Douglas-Jones is an Associate Professor at the IT University of Copenhagen, where she is the head of the Technologies in Practice research group and co-director of the ETHOSLab. She is an anthropologist of science and technology, working ethnographically on projects of at the intersection of IT, governance, audit cultures and ethics. She has published across anthropology and STS, editing collections on Capacity Building in International Comparison (2017, with Justin Shaffner), New Immortalities (2017, with Bob Simpson) and Toward an Anthropology of Data (2021, with Antonia Walford and Nick Seaver).Email: rdoj@itu.dk.

\section{Notes}

1. I shared a version of this vignette in an earlier publication (Douglas-Jones 2012). Since the online journal is no longer available, I have reformulated the ethnography for inclusion here.

2. FERCAP's work has been particularly concerned with the kind of issues that the TRUST Code of Conduct (2018) aims to address, but over the past decade they have also seen a growth in collaborations between countries within the region.

3. Amar Jesani, in addition to being a prominent and experienced public and community health worker, also serves on the international research ethics committee of Médicins Sans Frontières (MSF 2019).

4. I am aware of Paul Ricoeur's development of the concept of attestation and its conceptual relationship to testimony (Griesch 1995), but do not develop it here.

\section{References}

Ballestero, A. 2017. 'Capacity as Aggregation: Promises, Water and a Form of Collective Care in Northeast Brazil'. The Cambridge Journal of Anthropology 35 (1): 31-48. doi:10.3167/cja.2017.350104.

CIOMS (Council for International Organisations of Medical Sciences). 2016. International Ethical Guidelines for Health-Related Research Involving Humans. Geneva: CIOMS.

Coopmans, C., J. Vertesi, M. E. Lynch and S. Woolgar. 2014. Representation in Scientific Practice Revisited. Cambridge, MA: MIT Press. 
Daston, L. and P. Galison. 1992. 'The Image of Objectivity'. Representations 40: 81-128. doi:10.2307/2928741.

Derrida, J. 2005. 'Sovereignties in Question'. In T. Dutoit and O. Pasenen (eds), The Poetics of Paul Celan. New York: Fordham University Press, 65-97.

Douglas-Jones, R. 2012. 'A Single Broken Thread: Integrity, Trust and Accountability in Asian Ethics Committees'. Durham Anthropology Journal 18 (2): 13-27.

Douglas-Jones, R. 2017. 'Building Capacity in Ethical Review: Compliance and Transformation in the Asia-Pacific Region'. The Cambridge Journal of Anthropology 35 (1): 49-66. doi:10.3167/cja.2017.350105.

EC (European Commission). 2018. 'Ethics'. https://ec.europa.eu/programmes/ horizon2020/en/h2020-section/ethics (accessed 4 February 2020).

European Medicines Agency (EMA). 2012. Reflection Paper on Ethical and GCP Aspects of Clinical Trials of Medicinal Products for Human Use Conducted Outside of the EU/EEA and Submitted in Marketing Authorisation Applications to the EU Regulatory Authorities. EMA/121340/2011.

Ezrahi, Y. 1990. The Descent of Icarus: Science and the Transformation of Contemporary Democracy. Cambridge, MA: Harvard University Press.

Fassin, D. 2008. 'The Humanitarian Politics of Testimony: Subjectification through Trauma in the Israeli-Palestinian Conflict'. Cultural Anthropology 23 (3): 531-558. doi:10.1111/j.1548-1360.2008.00017.x.

Givoni, M. 2014. 'The Ethics of Witnessing and the Politics of the Governed'. Theory, Culture and Society 31 (1): 123-142. https://doi.org/10.1177/0263276413488633.

Givoni, M. 2016. The Care of the Witness: A Contemporary History of Testimony in Crisis. Cambridge: Cambridge University Press.

Griesch, J. 1995. 'Testimony and Attestation'. Philosophy and Social Criticism 21 (5): 81-98. https://doi.org/10.1177/0191453795021005-607.

Hamburger, A. 2004. 'The New Censorship: Institutional Review Boards'. The Supreme Court Review: 291-354. doi:10.2139/ssrn.721363.

Haraway, D. 1997.Modest_Witness@Second_Millennium.FemaleMan ${ }^{\odot}{ }_{\text {Meets_OncoMouse }}{ }^{\mathrm{TM}}$ : Feminism and Technoscience. New York: Routledge.

Holbraad, M. and R. Willerslev. 2007. 'Afterword on Transcendental Perspectivism: Anonymous Viewpoints from Inner Asia'. Inner Asia 9: 329-345. doi:10.2307/23614998.

Jacob, M.-A. and A. Riles. 2007. 'The New Bureaucracies of Virtue: Introduction'. PoLAR: Political and Legal Anthropology Review 30 (2): 181-191. doi:10.2307/24497373.

Jacobs, N. 2019. 'A Moral Obligation to Proper Human Experimentation'. Paper presented at 'Research Ethics Committees: Origins, Development and Beyond', organized by H. Tinnerholm Ljungberg, M. Ramsey and F. Lee, Department of History of Science and Ideas, Uppsala University, 28-29 May.

Jesani, A. 2009. 'Editorial: Ethics in Ethics Committees - Time to Share Experiences, Discuss Challenges and Do a Better Job'. Indian Journal of Medical Ethics 6 (2): 1-2. doi:10.20529/IJME.2009.022.

Lamont, M. and K. Huutoniemi. 2011. 'Comparing Customary Rules of Fairness: Evaluative Practices in Various Types of Peer Review Panels'. In C. Camic, N. Gross and M. Lamont (eds), Social Knowledge in the Making. Chicago: University of Chicago Press.

Marcus, G. E. 2005. 'The Anthropologist as Witness in Contemporary Regimes of Intervention. Cultural Politics 1 (1): 31-49. https://doi.org/10.2752/174321905778054890. 
MSF (Médicins Sans Frontières). 2019. MSF Ethics Review Board Members. http:// hdl.handle.net/10144/619265 (accessed 6 March 2020).

Nordling, L. 2018. 'EU Crackdown on “Ethics Dumping”'. Nature 559 (5 July): 17-18.

Nuffield Council on Bioethics. 2002. The Ethics of Research Related to Healthcare in Developing Countries. London: Nuffield Council on Bioethics.

Nuffield Council on Bioethics. 2005. The Ethics of Research Related to Healthcare in Developing Countries: A Follow-up Discussion Paper. London: Nuffield Council on Bioethics.

Petryna, A. 2005. 'Ethical Variability: Drug Development and Globalizing Clinical Trials'. American Ethnologist 32: 183-197. https://doi.org/10.1525/ae.2005.32.2.183.

Petryna, A. 2009. When Experiments Travel: Clinical Trials and the Global Search for Human Subjects. Princeton, NJ: Princeton University Press.

Redfield, P. 2006. 'A Less Modest Witness: Collective Advocacy and Motivated Truth in a Medical Humanitarian Movement'. American Ethnologist 33 (1): 3-26. doi:10.2307/3805313.

Reed-Danahay, D. 2017. 'Participating, Observing, Witnessing. In S. Coleman, S. B. Hyatt and A. Kingsolver (eds), The Routledge Companion to Contemporary Anthropology. New York: Routledge, 57-71.

Rose, D. B. 2015. 'Becoming-Witness'. In D. Peterson and M. Bekoff (eds) The Jane Effect: Celebrating Jane Goodall. San Antonio, TX: Trinity University Press, 231-232.

Shapin, S. 1994. A Social History of Truth. Chicago, IL: Chicago University Press.

Shapin, S. and S. Schaffer. [1985] 2011. Leviathan and the Air Pump: Hobbes, Boyle and the Experimental Life. Princeton, NJ: Princeton University Press.

Stark, L. 2011. 'Meetings by the Minute(s): How Documents Create Decisions for Institutional Review Boards'. In C. Camic, N. Gross and M. Lamont (eds), Social Knowledge in the Making. Chicago, IL: University of Chicago Press, 233-256.

Stark, L. 2012. Behind Closed Doors: IRBs and the Making of Ethical Research. Chicago, IL: University of Chicago Press.

Strathern, M. 2000. Audit Cultures: Anthropological Studies in Accountability and Ethics in the Academy. London: Routledge.

Strathern, M. 2014. Learning to See in Melanesia. Chicago, IL: Hau Books.

TRUST. 2018. 'Global Code of Conduct for Research in Resource-Poor Settings'. http:// www.globalcodeofconduct.org/wp-content/uploads/2018/05/Global-Code-ofConduct-Brochure.pdf.

Van Dooren, T. 2014. 'C for Care'. https://www.youtube.com/watch?v=eLaHmplgq0U (accessed 1 December 2019).

Warlow, C. 2004. 'Clinical Research under the Cosh Again'. British Medical Journal 329: 241-242.

WHO (World Health Organization). 2011. Standards and Operational Guidance for Ethics Review of Health-Related Research with Human Participants. Geneva: WHO.

Wilson, D. 2014. The Making of British Bioethics. Manchester: Manchester University Press.

World Medical Association. [1964] 2013. 'Declaration of Helsinki: Ethical Principles for Medical Research Involving Human Subjects'. JAMA 310 (20): 2191-2194. doi:10.1001/jama.2013.281053. 